\title{
Laser-Scribed Graphene Electrodes Derived from Lignin for Biochemical Sensing
}

Yongjiu Lei, ${ }^{\dagger}$ Aya H. Alshareef, ${ }^{\dagger}$ Wenli Zhao, ${ }^{\dagger}$ Sahika Inal ${ }^{*}, *$

${ }^{\dagger}$ Materials Science and Engineering, Physical Science and Engineering Division, King Abdullah University of Science and Technology (KAUST), Thuwal 23955-6900, Saudi Arabia.

$\$$ Biological and Environmental Science and Engineering Division, King Abdullah University of Science and Technology (KAUST), Thuwal 23955-6900, Saudi Arabia "E-mail: sahika.inal@kaust.edu.sa

\begin{abstract}
Laser scribing of porous graphene electrodes on flexible substrates is of great interest for developing disposable electrochemical biosensors. In this work, we present a new patterning process for highly conductive nitrogen-doped graphene derived from a lignin-based precursor. $\mathrm{A} \mathrm{CO}_{2}$ laser scribing process was performed under ambient conditions to produce the porous graphene electrodes from lignin. The obtained nitrogendoped laser-scribed graphene (N-LSG) is binder-free, hierarchical, and conductive. The interconnected carbon network displayed enhanced electrochemical activity with improved heterogeneous electron transfer rate. These features can be attributed to the highconductivity of porous N-LSG (down to $2.8 \Omega$ per square) and its enriched active edge plane sites. Furthermore, the N-LSG electrodes were decorated with MXene/Prussian Blue $\left(\mathrm{Ti}_{3} \mathrm{C}_{2} \mathrm{~T}_{x} / \mathrm{PB}\right)$ composite via a simple spray coating process, designed for sensitive
\end{abstract}


detection of analytes. The $\mathrm{Ti}_{3} \mathrm{C}_{2} \mathrm{~T}_{x} / \mathrm{PB}$ modified N-LSG electrodes were functionalized with catalytic enzymes for detecting glucose, lactate, and alcohol. The enzyme $/ \mathrm{Ti}_{3} \mathrm{C}_{2} \mathrm{~T}_{x} / \mathrm{PB} / \mathrm{N}$-LSG electrodes exhibited remarkably enhanced electrochemical activity toward the detection of these biomarkers, making them highly competitive with previously reported on-chip carbon-based biosensors. Therefore, our sensors demonstrate excellent potential for applications in personalized healthcare.

KEYWORDS: lignosulfonate, laser-scribed graphene, high conductivity, biosensor, MXene, glucose, lactate, alcohol 


\section{INTRODUCTION}

Carbon-based materials, including graphene, mesoporous carbons, and carbon nanotubes have been widely developed as active materials for electrochemical sensors. ${ }^{1,2}$ Especially, graphene-based materials showed excellent potential in electrochemical sensing of biomolecules opening the door toward point-of-care monitoring, and personalized sensors. ${ }^{3,4}$ Normally, specific surface area, mobility of charge carrier , and available edge-plane sites of graphene electrodes have a direct impact on the analytical performance of sensors. ${ }^{5,6}$ Numerous researchers have claimed that graphene-based electrodes with 3D interconnected carbon network show enhanced electrochemical performance compared with conventional planar graphene electrodes, which can be attributed to its large surface area, 3D charge transport pathways, abundant edge plane sites, and highly efficient mass transport. ${ }^{7-10}$ Laser scribed graphene (LSG) through direct conversion of polymers or graphene oxide into graphene by a computer-controlled laser scribing process, is a promising platform for patterned electrochemical (bio)sensor. ${ }^{11-13}$ LSG offers an ideally binder-free, hierarchical, conductive 3D interconnected carbon network, while maintaining the unique $2 \mathrm{D}$ functionality of graphene, thus making it an ideal substrate to interface proteins such as enzymes or antibodies. LSG has high electronic conductivity allowing for efficient transport of electrons generated in biochemical reactions.

In previous studies, the Tour group demonstrated a low-cost approach for transforming wood into porous LSG electrodes using $\mathrm{CO}_{2}$ laser scribing under a special reducing 
atmosphere. ${ }^{14}$ A high electrical conductivity $(\approx 10 \Omega$ per square) LSG was achieved, which resulted in high-performance hydrogen and oxygen evolution reactions for overall water splitting. Subsequently, the same group extended the laser scribing technology to heatsensitive materials with high cellulose content by adding fire retardants. ${ }^{15}$ High conductivity LSG ( $\leq 5 \Omega$ per square) was obtained on biodegradable substrates with multiple-step lasing process. Following this, Kim's group reported a method to transform arbitrary woods and leaves into green LSG electronics by femtosecond lasers writing under ambient conditions in the absence of additives. ${ }^{16}$ The resulting LSG showed good electrical conductivity (10 $\Omega$ per square) and high patterning resolution (linewidth of $40 \mu \mathrm{m}$ ). However, there is a random fluctuation in the performance of LSG derived from natural polymers (like woods, leaves, and coconut shells), which is a consequence of variable lignin content in these materials. ${ }^{15}$ In our studies, we find that the composition and content of lignin in the precursor strongly affect the surface microstructure and charge transfer rate of LSG, and hence its electrochemical performance. For instance, the low content of lignin ( $\leq 36 \%$ typically) in natural polymers leads to loosely connected conducting network of LSG substrate, greatly compromising the intrinsic mass and charge transfer, and hence decreasing the electrochemical activity. ${ }^{17,18}$ Further, lignosulfonate, the precursor of the principal commercially lignin types, exhibits good solubility and numerous aromatic rings. ${ }^{19}$ Meanwhile, lignosulfonate is available in plentiful supply and low-cost due to its wide availability from pulp and paper industry, making it an ideal carbon provider for highquality LSG. Therefore, a more efficient and convenient method of synthesis of LSG from 
natural polymers with higher quality and repeatability is urgently needed.

Herein we report the fabrication of disposable on-chip multiplex electrochemical sensors using computer-controlled $\mathrm{CO}_{2}$ laser scribing technology that transforms ligninbased precursors into nitrogen-doped LSG (N-LSG) patterns with porous 3D morphology and high electron transfer rate. Commercial lignosulfonate with good solubility and a high proportion of aromatic rings was chosen as the major carbon provider. To achieve optimal electrochemical performance, nitrogen doping through urea addition is an effective strategy to tune the host material properties. ${ }^{20}$ Our N-LSG electrodes displayed enhanced electrochemical activity for fast heterogeneous electron transfer. Further, two-dimensional MXene $\left(\mathrm{Ti}_{3} \mathrm{C}_{2} \mathrm{~T}_{x}\right)$ nanosheets were introduced into the N-LSG electrodes as well as a MXene/Prussian blue $\left(\mathrm{Ti}_{3} \mathrm{C}_{2} \mathrm{~T}_{x} / \mathrm{PB}\right)$ composite synthesized for detecting hydrogen peroxide. Finally, these electrodes were functionalized with different catalytic enzymes for detection of glucose, lactate, and alcohol. The enzyme $/ \mathrm{Ti}_{3} \mathrm{C}_{2} \mathrm{~T}_{x} / \mathrm{PB} / \mathrm{N}-\mathrm{LSG}$ electrodes exhibited significantly enhanced electrochemical activity toward the detection of these biomarkers compared to other cellulose-derived materials and laser-scribed ones.

\section{RESULTS AND DISCUSSIONS}

\subsection{Graphene Electrodes Derived from Lignin}

The direct-write laser scribing process of nitrogen-doped laser scribed graphene (NLSG) patterns is schematically illustrated in Figure 1. First, precursor films were processed in ambient by blade-coating from homogeneous solutions (containing lignosulfonate, polyvinyl alcohol (PVA), urea, distilled water) on polymer substrates (Figure S1, 
Supporting Information). The films were then dried for $24 \mathrm{~h}$ at room temperature to volatilize the solvents. Next, the films were transformed into patterned N-LSG electrodes by a computer-controlled $\mathrm{CO}_{2}$ laser scribing process carried out under ambient conditions (Figure 1, step 3). The design of active geometric size and structure for the N-LSG electrodes is demonstrated in Figure S2. The working electrodes were modified with $\mathrm{Ti}_{3} \mathrm{C}_{2} \mathrm{~T}_{x} / \mathrm{PB}$ by a spraying coating process (see synthesis details in the Supporting Information). As the blade-coated precursor layer in the untransformed region could be easily dissolved in water, the uncarbonized region (non-patterned space) can be removed by using a water lift-off process (recorded in Video S1 in the Supporting Information), leaving the N-LSG with the desired five-electrode patterns on the substrate. Finally, the sensor chips were assembled by immobilizing the catalytic enzymes to access enzyme $/ \mathrm{Ti}_{3} \mathrm{C}_{2} \mathrm{~T}_{x} / \mathrm{PB} / \mathrm{N}-\mathrm{LSG}$ electrodes.

The tilted-view scanning electron microscopy (SEM) image (Figure S3) showed negligible thickness change of the N-LSG film obtained with $4.8 \% \mathrm{CO}_{2}$ laser power (henceforth named N-LSG4.8). It is known that during the laser scribing process, gaseous products rapidly diffuse out of the film. ${ }^{21}$ The process led to a 3D interconnected network of porous N-LSG4.8 film (Figure 2a) and numerous active edge-plane sites (Figure 2b). The transmission electron microscopy (TEM) image (Figure 2c) proves the abundance of edge-plane sites contains in the onion-like graphitic carbon nanostructure, which are composed of multiple long graphene layers, and expected to enhance electron transfer behavior. The high-resolution TEM (HR-TEM) image demonstrated that the average 
lattice space of N-LSG is $\sim 3.56 \AA$ (Figure $2 \mathrm{~d}$ ), which is expanded compared to conventional graphite materials as a result of doping with nitrogen and oxygen atoms. ${ }^{22}$ Energy dispersive X-ray (EDX) elemental mapping of the N-LSG4.8 sample (Figure 3ad) suggests that nitrogen and oxygen atoms are homogenously embedded in N-LSG4.8 carbon framework with 3D architecture. The graphitic structures of LSG and N-LSG4.8 were characterized by the powder X-ray diff raction (XRD) (Figure S4). The broad peak around $2 \theta=25.9^{\circ}$ of both samples could be indexed to the (002) diffractions of the hexagonal graphite (JCPDS no. 41-1487), indicating an average interlayer spacing of 0.34 nm; asymmetry of the (002) peak of N-LSG4.8 demonstrates the disordered amorphous structure and defects resulting from nitrogen doping. ${ }^{20}$

The chemical composition and state of N-LSG was studied by X-ray photoelectron spectroscopy (XPS). The survey scan shows N-LSG has a primary graphitic C 1s (284.3 eV), O 1s peak (532 eV), and N 1s peak (400 eV) (Figure S5). N content in N-LSG estimated from XPS data is 1.6 at\% (Figure S5a). C 1s core-level XPS spectrum ranging from $282-295 \mathrm{eV}$ can be deconvoluted into five peaks (Figure S5b). ${ }^{20}$ The signal at 284.3 $\mathrm{eV}$ could be ascribed to $\mathrm{sp}^{2}-\mathrm{C}$ atoms $(\mathrm{C}=\mathrm{C})$. The other four peaks centered at 284.6, 285.3, 288.3 and $291.3 \mathrm{eV}$ correspond to the $\mathrm{sp}^{3}-\mathrm{C}, \mathrm{C}-\mathrm{N}, \mathrm{C}=\mathrm{O}$, and O-C-O groups, respectively. The results provide further evidence that nitrogen was successfully integrated into the graphene structure.

It is interesting to note that increasing applied laser power provide a positive effect to 
increase the porosity of the N-LSG (Figure S6). As the power of the laser increased, more gaseous products were produced and released faster. Raman spectroscopy was applied to study the structure and quality of carbon-based materials. Three dominating peaks of Figure 4a were observed: $\mathrm{D}$ peak (corresponds to bent $\mathrm{sp}^{2}$ carbon bonds, number of defects/functional groups) at $1360 \mathrm{~cm}^{-1}, \mathrm{G}$ peak (the first order scattering of the $\mathrm{E}_{2 \mathrm{~g}}$ mode) at $1570 \mathrm{~cm}^{-1}$, and 2D peak (the second-order two phonon process) at $2700 \mathrm{~cm}^{-1} .{ }^{23}$ The threshold power of the $\mathrm{CO}_{2}$ laser was $2.8 \%$, which initiated the graphitization of lignin/PVA/urea film. The reduced D peak intensity and D/G intensity ratio with an increase in laser power from $2.8 \%$ to $4.8 \%$ (Figure $4 \mathrm{~b}$ ) indicate an enhancement in the quality of the graphene formed in the N-LSG film. Further, Raman spectroscopy was utilized to determine the crystalline size along the $a$ axis $\left(L_{\mathrm{a}}\right)$ of carbon-based materials. The peak intensity ratio of $\mathrm{D}$ band to $\mathrm{G}$ band $\left(I_{\mathrm{D}} / I_{\mathrm{G}}\right)$ is associated with the in-plane $L_{\mathrm{a}}$. The average $L_{\mathrm{a}}$ values, calculated from the ratio of $\mathrm{I}_{\mathrm{D}} / \mathrm{I}_{\mathrm{G}}$, were displayed in Figure $4 \mathrm{c}$ (the calculation method is shown in Experimental section). ${ }^{24}$ A maximum of $L_{\mathrm{a}}=36.1 \mathrm{~nm}$ was achieved corresponding to the lowest $I_{\mathrm{D}} / I_{\mathrm{G}}$ ratio $(0.33$, laser power at $4.8 \%)$.

The $2 \mathrm{D}$ peak intensity is very sensitive to the thickness of graphene layers. The $I_{\mathrm{G}} / I_{2 \mathrm{D}}$ ratio is thus commonly used to characterize the effective thickness of the graphene layers. ${ }^{25}$ For example, in the case presented in Figure $4 \mathrm{~b}$, the N-LSG4.8 film has the smallest $I_{\mathrm{G}} / I_{2 \mathrm{D}}$ ratio, corresponding to the lowest number of graphene layers. Further, the processes generating $\mathrm{D}$ and 2D peaks are competitive because of the mechanism of double electronphonon resonance, and hence the $I_{\mathrm{G}} / I_{2 \mathrm{D}}$ ratio increases with the amount of intrinsic defects 
(increase of D peak intensity). Since the N-LSG4.8 film with the lowest $I_{\mathrm{G}} / I_{2 \mathrm{D}}$ ratio has fewer structural defects, it has better electronic transport properties as shown from the sheet resistance results in Figure 4d. The N-LSG film exhibits better conductivity compared with other polymer-derived LSG, a minimum value of $2.8 \Omega$ per square was achieved at a laser power of $4.8 \%$. Further increase in the laser power damages the polymer substrate, and smoke fumed up during the laser scribed process, due to partial oxidation of lignosulfonate in air.

\subsection{Electrochemical Activity}

A typical three-electrode system ( $\mathrm{Pt}$ wire: counter electrode, $\mathrm{Ag} / \mathrm{AgCl}$ : reference electrode) was applied to evaluate the electrochemical activity of our N-LSG working electrode. We recorded the cyclic voltammetry (CV) curves using two different redoxactive mediators, inner-sphere ferrocyanide $\left(\left[\mathrm{Fe}(\mathrm{CN})_{6}\right]^{4-}\right)$ and outer-sphere hexaammineruthenium $\left(\left[\mathrm{Ru}\left(\mathrm{NH}_{3}\right)_{6}\right]^{3+}\right)$, and determined the heterogeneous electron transfer (HET) rate constant, $\mathrm{k}^{0}$, between the N-LSG electrode surface and the redox mediators. Figure 5a shows the CV profiles of geometrically identical LSG4.8 and N-LSG4.8 electrodes in $\left[\mathrm{Fe}(\mathrm{CN})_{6}\right]^{4-}$ aqueous solution at a concentration of $5 \times 10^{-3} \mathrm{M}$ in $0.1 \mathrm{M} \mathrm{KCl}$ buffer electrolyte. The CV curves demonstrate the charge transfer process between the working electrode and the ferri/ferrocyanide, suggesting the corresponding redox behavior of the mediators. The voltammetry profiles revealed that ferrocyanide showed a lower the peak potential separation $\left(\Delta \mathrm{E}_{\mathrm{p}}\right)$ value for the N-LSG4.8 $(67 \mathrm{mV})$ electrode compared to the LSG4.8 $(81 \mathrm{mV})$ electrode indicating a faster HET rate, which is due to N-LSG4.8 
electrode's better electrical conductivity compared with the un-doped LSG4.8 electrode (see Figure S7, Supporting information). Note that we also measured a small series resistance of $10 \mathrm{Ohm} \mathrm{cm}^{2}$ for the N-LSG4.8 electrode, in accordance with its high conductivity (see Figure S8, Supporting information). The large redox current density of N-LSG4.8 indicates a fast electron transfer mechanism and large electrochemically active surface area. Similar results were obtained when the experiments were performed with $\left[\mathrm{Ru}\left(\mathrm{NH}^{3}\right)_{6}\right]^{3+}$ : Figure $5 \mathrm{c}$ shows that the N-LSG4.8 electrode exhibits smaller $\Delta$ Ep value (i.e., $72 \mathrm{mV}$ ) and larger redox current density than that of the LSG4.8 electrode $(84 \mathrm{mV})$, indicating a faster electron transfer mechanism for the former. ${ }^{11}$

We next recorded scan rate dependent $\mathrm{CV}$ curves (Figure $5 \mathrm{~b}$ and d). The shift in peak position with the change of the scan rate indicates a quasi-reversible electrochemical reaction. The peak currents $\left(I_{\mathrm{p}}\right)$ were proportional to the square root of the scan rate $\left(v^{1 / 2}\right)$, inferring that the mass transfer process for both redox mediators is controlled by diffusion. Using this data, we estimated the electrochemically active surface area $\left(\mathrm{S}, \mathrm{cm}^{2}\right)$ of the NLSG4.8 electrode using Randles-Sevcik equation: ${ }^{26}$

$$
I_{\mathrm{p}}=2.69 \times 10^{5} S D^{1 / 2} n^{3 / 2} v^{1 / 2} C
$$

in which $I_{\mathrm{p}}, D, n$, and $C$ represent peak current (A), diffusion constant of the redox mediator, electron transfer number, and mediator concentration $\left(\mathrm{mol} \mathrm{cm}{ }^{-3}\right)$, respectively. ${ }^{27}$ The average electrochemically active surface area for the N-LSG4.8 electrode was calculated to be $12.376 \mathrm{~mm}^{2}$, around two times higher than its geometric surface area $\left(7 \mathrm{~mm}^{2}\right)$. We then determined the HET rate constant $\left(\mathrm{k}^{0}\right)$ in $\mathrm{cm} \mathrm{s}^{-1}$ using the equation (2): ${ }^{28}$ 


$$
\psi=\mathrm{k}^{0} \sqrt{\frac{R T}{\pi \mathrm{nDD}_{0} v}} \text { or } \psi=\mathrm{Ck}^{0} v^{-1 / 2}
$$

in which $\Psi, \mathrm{R}, \mathrm{T}$, and $\mathrm{F}$ represent dimensionless parameter, universal gas constant, absolute temperature $(\mathrm{K})$, and Faraday constant, respectively, while $\mathrm{k}^{0}$ can be calculated on the basis of the plot of $\Psi v s . \mathrm{Cv}^{-1 / 2}$. Five different N-LSG4.8 electrodes were tested under the same conditions, and all the electrochemical parameters were calculated, as summarized in Table 1. The small magnitude of the relative standard deviation of $\mathrm{k}^{0}$ suggests a good reproducibility, and the average $\mathrm{k}^{0}$ value for $\left[\mathrm{Fe}(\mathrm{CN})_{6}\right]^{4-}$ was $0.00903 \mathrm{~cm} \mathrm{~s}^{-1}$. This is superior to most of the reported carbon-based materials, such as commercially available edge-plane pyrolytic graphite $\left(0.00260 \mathrm{~cm} \mathrm{~s}^{-1}\right)$, basal-plane pyrolytic graphite $(0.00033 \mathrm{~cm}$ $\left.\mathrm{s}^{-1}\right)$, and LSG from polyimide film $\left(0.0044 \mathrm{~cm} \mathrm{~s}^{-1}\right) \cdot{ }^{11}$ The average $\mathrm{k}^{0}$ value for $\left[\mathrm{Ru}\left(\mathrm{NH}_{3}\right)_{6}\right]^{3+}$ was estimated to be $0.00863 \mathrm{~cm} \mathrm{~s}^{-1}$, exceeding the $\mathrm{k}^{0}$ of the classical nanostructured carbons like quasi-graphene $\left(0.00158 \mathrm{~cm} \mathrm{~s}^{-1}\right)$, basal-plane pyrolytic graphite $\left(0.0038 \mathrm{~cm} \mathrm{~s}^{-1}\right)$, and edge-plane pyrolytic graphite $\left(0.00877 \mathrm{~cm} \mathrm{~s}^{-1}\right)$ electrodes. ${ }^{29,30}$

\subsection{Biosensor Performance}

In 2007, Whitesides et al. proposed a new research direction in analytical chemistry based on the development of low-cost, disposable, and miniaturized devices to provide quick and simple diagnostics. ${ }^{31}$ They developed a paper-based portable device as an alternative to advanced laboratory instruments, especially for use in remote regions, emergencies, or for home healthcare applications. Following this work, methods like dropcasting, inkjet printing, screen printing, direct pencil drawing, laser scribing process and 
wire or fiber attachment were developed to obtain miniaturized electrodes on paper substrates. ${ }^{32-34}$ However, the conductivity of these paper-based electrodes is not high enough, resulting in sluggish HET rate, which hinders their application as a reliable, sensitive, and cost-efficient sensing platform for scalable fabrication. Meanwhile, there is a significant need for noninvasive monitoring of important disease markers in biological fluids. ${ }^{35-37}$ Sweat, containing numerous biochemical markers and providing relatively easy collection (compared to blood), is an easily accessible human biofluid for noninvasive monitoring of an individual's health state. ${ }^{38}$ Despite massive efforts exerted toward the development of sweat-based sensors, noninvasive sweat-based monitoring is still far from achieving its desired purpose ${ }^{39}$ Compared with its wearable counterparts, the disposable on-chip sensor is more convenient for sweat analysis because it uses small volumes of sweat and is sufficiently low-cost. ${ }^{40}$ Considering such a situation, the lignin-derived NLSG electrode, which has excellent HET rate, 3D connected network of graphene, plenty edge-plane sites and low-cost fabrication, is a perfect candidate for sweat analysis.

To investigate the performance of the N-LSG4.8 films as disposable electrochemical biosensing electrodes, we used $\mathrm{Ti}_{3} \mathrm{C}_{2} \mathrm{~T}_{x} / \mathrm{PB}$ and catalytic enzymes to modify the working electrodes for selective detection of glucose, lactate, and alcohol, which are molecules present in sweat, and markers of diabetes, indicators of athletic performance, and of alcoholism or drunk-state, respectively. ${ }^{38}$ Alshareef et al. have recently shown that $\mathrm{Ti}_{3} \mathrm{C}_{2} \mathrm{~T}_{x} / \mathrm{PB}$ composites have exhibited improved an electrochemical $\mathrm{H}_{2} \mathrm{O}_{2}$ detection capability compared to graphene/PB and carbon nanotubes/PB composites. ${ }^{41}$ In this work, 
we introduced $\mathrm{Ti}_{3} \mathrm{C}_{2} \mathrm{~T}_{x} / \mathrm{PB}$ composites (synthesis method, Supporting Information) onto NLSG4.8 electrodes using spray coating. Figure $6(\mathrm{a}, \mathrm{b})$ show SEM images of $\mathrm{Ti}_{3} \mathrm{C}_{2} \mathrm{~T}_{x}$ nanosheets and as-synthesized $\mathrm{Ti}_{3} \mathrm{C}_{2} \mathrm{~T}_{x} / \mathrm{PB}$ composites. Uniformly distributed $\mathrm{PB}$ nanoparticles were dispersed on the $\mathrm{Ti}_{3} \mathrm{C}_{2} \mathrm{~T}_{x}$ nanosheet (also confirmed by TEM and SEM in Figure S9). Figure $6(\mathrm{c}, \mathrm{d})$ show the $\mathrm{Ti}_{3} \mathrm{C}_{2} \mathrm{~T}_{x} / \mathrm{PB}$-decorated N-LSG4.8 electrode with the $\mathrm{Ti}_{3} \mathrm{C}_{2} \mathrm{~T}_{x} / \mathrm{PB}$ and LSG tightly integrated upon the spray coating process. The $\mathrm{Ti}_{3} \mathrm{C}_{2} \mathrm{~T}_{x} / \mathrm{PB}-$ decorated N-LSG4.8 electrode showed enhanced electrocatalytic activity toward $\mathrm{H}_{2} \mathrm{O}_{2}$ at an applied potential of $-0.1 \mathrm{~V}$. The current measured scales linearly with $\mathrm{H}_{2} \mathrm{O}_{2}$ concentration in the range of $0 \sim 10 \mathrm{mM}$ with a sensitivity of $212.5 \mu \mathrm{A} \mathrm{mM}^{-1} \mathrm{~cm}^{-2}$ (Figure S10a-b in Supporting Information).

Glucose sensor based on sweat analysis is a convenient and cost-effective technique for diagnosing diabetes mellitus. ${ }^{40}$ In this work, the glucose oxidase (Gox) is immobilized onto a patterned $\mathrm{Ti}_{3} \mathrm{C}_{2} \mathrm{~T}_{x} / \mathrm{PB} / \mathrm{N}$-LSG4.8 electrode, resulting in a disposable glucose sensor with high selectivity. Artificial sweat containing glucose with concentration range of 10 $\mu \mathrm{M}$ to $5.3 \mathrm{mM}$ was used to calibrate the glucose sensor, and a high electrochemical sensitivity of $49.2 \mu \mathrm{A} \mathrm{mM}^{-1} \mathrm{~cm}^{-2}$ is achieved (Figure 7a, Figure S11a). The detection limit of the glucose sensor was measured to be $0.3 \mu \mathrm{M}$ of glucose at an $\mathrm{S} / \mathrm{N}$ ratio of 3 (Figure S10c).

Sweat lactate originates from eccrine gland metabolism, and the lactate concentration in sweat varies with increasing exercise intensity from $\sim 10 \mathrm{mM}$ to as high as $\sim 25 \mathrm{mM}$. ${ }^{42,43}$ To render the $\mathrm{Ti}_{3} \mathrm{C}_{2} \mathrm{~T}_{x} / \mathrm{PB} / \mathrm{N}$-LSG4.8 electrode sensitive to lactate, we modified it with 
lactate oxidase (Lox). The sensor was calibrated using artificial sweat with lactate concentrations ranging from $0 \mathrm{mM}$ to $20 \mathrm{mM}$, resulting in electrochemical sensitivity of $21.6 \mu \mathrm{A} \mathrm{mM} \mathrm{m}^{-1} \mathrm{~cm}^{-2}$ (Figure $7 \mathrm{~b}$, Figure $\mathrm{S} 11 \mathrm{~b}$ ). The detection limit of this lactate sensor is $0.5 \mu \mathrm{M}$ of lactate at an $\mathrm{S} / \mathrm{N}$ ratio of 3 (Figure $\mathrm{S} 10 \mathrm{~d}$ ).

We next modified $\mathrm{Ti}_{3} \mathrm{C}_{2} \mathrm{~T}_{x} / \mathrm{PB} / \mathrm{N}-\mathrm{LSG} 4.8$ electrodes with alcohol oxidase (AOD). Noninvasive alcohol detection provides a convenient method to continuously monitor alcohol consumption for law enforcement personnel, public service, or personal consumers. The alcohol sensor was also calibrated using artificial sweat containing alcohol in concentrations that ranged from 0 to $50 \mathrm{mM}$, and high detection sensitivity of $5.78 \mu \mathrm{AmM}^{-}$ ${ }^{1} \mathrm{~cm}^{-2}$ is achieved (Figure 7c, Figure S11c). The inset in Figure 7c displays the calibration plot of this sensor.

Finally, four electrodes (glucose, lactate, and alcohol sensitive) were randomly chosen from the respective batches and tested in three iterations under the same experimental conditions. The glucose, lactate, and alcohol sensors were tested one by one in the $350 \mu \mathrm{M}$ of glucose, $10 \mathrm{mM}$ lactate, $20 \mathrm{mM}$ alcohol mixtures. The relative standard deviations (RSDs) of the glucose, lactate, and alcohol sensors were $3.4 \%, 5.7 \%$, and $5.4 \%$, respectively (Figure 7d-f), and the RSDs of electrode-to-electrode reproducibility of four electrodes were $5.9 \%, 3.8 \%$, and $1.7 \%$, respectively. The sensitivity, detection limit, and linear detection range of biosensors in this work were better than those of other printed onchip electrodes (Table S1 in Supporting Information) and cellulosic materials using laser scribing reported in the literature (Table S2 in Supporting Information). Note that the 
performance of these sensors relies on the use of $\mathrm{Ti}_{3} \mathrm{C}_{2} \mathrm{~T}_{x} / \mathrm{PB}$ as N-LSG4.8 electrode alone or when combined with $\mathrm{PB}$ has lower sensitivity and dynamic range towards all of the analytes (Figure S11). The integration of five electrodes (e.g., counter, reference and three working electrodes functionalized with different enzymes) on one chip (Figure 1, Figure S2b) is not only a design feature enabling multi-analyte detection from a single sweat sample, but also a low-cost approach avoiding additional material waste. Moreover, as the sweat collection procedure is tiring, interfacing the sweat with closely spaced electrodes on one substrate is more user-friendly. These results suggest $\mathrm{Ti}_{3} \mathrm{C}_{2} \mathrm{~T}_{x} / \mathrm{PB} / \mathrm{N}-\mathrm{LSG}$ electrodes to be a promising sensor platform due to their excellent conductivity, enriched active edge plane sites, and fast electron transfer kinetics for enzymes.

\section{Conclusion}

Disposable on-chip electrochemical sensors were fabricated using a laser-scribing process that transforms lignin-based precursors into nitrogen-doped graphene patterns. The key characteristics of N-LSG electrodes include porous 3D morphology, enriched active edge plane sites, and high electron transfer rates. The $\mathrm{Ti}_{3} \mathrm{C}_{2} \mathrm{~T}_{x} / \mathrm{PB}$ composites were introduced to detect $\mathrm{H}_{2} \mathrm{O}_{2}$ reliably and sensitively. The working electrodes were extended by using different enzymes for the corresponding biomarker detection, including glucose, lactate, and alcohol. The enzyme $/ \mathrm{Ti}_{3} \mathrm{C}_{2} \mathrm{~T}_{x} / \mathrm{PB} / \mathrm{N}-\mathrm{LSG}$ electrodes displayed significantly improved electrocatalytic activity in a wide concentration range toward detecting glucose, lactate, and alcohol. The greatly improved performance suggests that the lignin-based LSG electrode is an advanced platform for analysis of a wide range of biomarkers. We believe 
that the laser scribing methodology paves a new way for developing improved portable biosensors.

\section{EXPERIMENTAL SECTION}

N-LSG Electrode Fabrication. Typically, lignosulfonate (6 g), PVA (3.5 g), and urea (0.5

g) were added into $50 \mathrm{~mL}$ deionized water, following by stirring in a $70{ }^{\circ} \mathrm{C}$ oil bath for 10 hours. The lignin/PVA/urea film was coated onto the plastic substrates (e.g., polycarbonate, polyethylene terephthalate) prepared using a conventional doctor blading method, and the films were dried at ambient temperature for $24 \mathrm{~h}$. Here PVA polymer acts as the binder to get the uniform film. The thickness of the lignin/PVA/urea film was ca. $50 \mu \mathrm{m}$. The computer-controlled laser-scribing process was carried out on a $\mathrm{CO}_{2}$ laser cutting machine (10.6 $\mu \mathrm{m}, 75$ watt, Universal X-660 laser cutter platform, Austria), which transforms lignin/PVA/urea precursors film into patterned nitrogen-doped LSG (N-LSG) electrodes. The detailed parameters include laser pulse of $1000 \mathrm{dpi}^{\mathrm{inch}}{ }^{-1}$, scan rate of $3 \%$, and $z$ distance of $2.4 \mathrm{~mm}$. The applied laser power was set at $2.8 \%, 3.2 \%, 3.6 \%, 4.0 \%, 4.4 \%$, and $4.8 \%$ of the maximum power.

Preparation of Enzyme/Ti ${ }_{3} \mathbf{C}_{2} \mathbf{T}_{x} / \mathbf{P B} / \mathbf{N}-\mathbf{L S G} 4.8$ Electrodes: $\mathrm{Ti}_{3} \mathrm{C}_{2} \mathrm{~T}_{x} / \mathrm{PB} / \mathrm{N}-\mathrm{LSG} 4.8$ electrodes were prepared by a spray coating process. The concentration of the $\mathrm{Ti}_{3} \mathrm{C}_{2} \mathrm{~T}_{x} / \mathrm{PB}$ composites was ca.1.0 $\mathrm{mg} \mathrm{mL}^{-1}$ (see preparation details in the Supporting Information). In a typical way, $2 \mathrm{mg} \mathrm{mL}^{-1}$ chitosan solution with $2 w t \%$ acetic acid was mixed with enzyme (10 $\mathrm{mg} / \mathrm{mL}$ for glucose oxidase and alcohol oxidase, $20 \mathrm{mg} / \mathrm{mL}$ for lactate oxidase $)$ in $\mathrm{pH}=7$ 
phosphate-buffered saline, and diluted $0.5 \mathrm{wt} \%$ aqueous glutaraldehyde with a volume ratio of 3:5:2. Then, $5 \mu \mathrm{L}$ of the above mixture was casted onto the $\mathrm{Ti}_{3} \mathrm{C}_{2} \mathrm{~T}_{x} / \mathrm{PB} / \mathrm{N}-\mathrm{LSG} 4.8$ electrode, followed by drying at room temperature overnight. The as-prepared enzyme $/ \mathrm{Ti}_{3} \mathrm{C}_{2} \mathrm{~T}_{x} / \mathrm{PB} / \mathrm{N}-\mathrm{LSG} 4.8$ sensors were stored at $4{ }^{\circ} \mathrm{C}$ for further use.

Physicochemical Characterization. The morphology of the LSG and MXene or MXene/PB samples were investigated by field emission scanning electron microscope (SEM) (Merlin, Zeiss, Germany) and transmission electron microscope (TEM) (Titan 80300 ST, FEI). Micro-Raman spectrometer (cobalt laser of $473 \mathrm{~nm}$, LabRAM ARAMIS, Horiba-Jobin Yvon) was used for Raman spectroscopy measurements. The crystalline size along the $a$ axis $\left(L_{\mathrm{a}}\right)$ was calculated from the peak intensity ratio of D band and $\mathrm{G}\left(I_{\mathrm{D}} / I_{\mathrm{G}}\right)$ through the following equation:

$$
L_{a}=\left(2.4 \times 10^{-10}\right) \times \lambda_{l}^{4} \times\left(\frac{I_{D}}{I_{G}}\right)^{-1}
$$

A four-point probe set-up (RZ2001i, Ozawa Science Company) is used to determine the resistance of the films. XPS analysis was conducted on a photoelectron spectrometer (Kratos Axis Supra, Shimadzu, Japan). XRD measurements were conducted with a Bruker D8 Advance diffractometer with $\mathrm{Cu}-\mathrm{K} \alpha$ radiation $(\lambda=1.5406 \AA)$.

Electrochemical Measurements: CHI660D workstation (CHI Instruments, USA) was used for recording chronoamperometry (CA) and cyclic voltammetry (CV) curves. The electrochemical activity measurements of LSG electrodes were conducted with a threeelectrode setup using $\mathrm{Ag} / \mathrm{AgCl}(1 \mathrm{M} \mathrm{KCl})$ as reference electrode and $\mathrm{Pt}$ wire as counter 
electrode. Calibration of all the biosensors was conducted by measuring the chronoamperometric response 40 seconds after the application of a potential at $-0.1 \mathrm{~V}$ vs (home-made) $\mathrm{Ag} / \mathrm{AgCl}$ in the artificial sweat solution (artificial sweat containing $3 \mathrm{mM}$ of $\mathrm{NH}_{4} \mathrm{Cl}, 5 \mathrm{mM}$ of $\mathrm{KCl}$, and $100 \mathrm{mM}$ of $\mathrm{NaCl}$ ). All the sensor testing experiments were carried out in a three-electrode mode, wherein in-plane home-made $\mathrm{Ag} / \mathrm{AgCl}$ was used as the reference electrode and N-LSG as the counter electrode. $\mathrm{Ag} / \mathrm{AgCl}$ ink (product \#011464, ALS Co., Ltd, Japan) was painted onto the N-LSG4.8 electrode to prepare our $\mathrm{Ag} / \mathrm{AgCl}$ reference electrode, followed by drying in an electronic oven at $100{ }^{\circ} \mathrm{C}$ for 15 minutes.

\section{ASSOCIATED CONTENT}

\section{Supporting Information}

The Supporting Information is available free of charge on the ACS Publications website at DOI:

The synthesis details of $\mathrm{Ti}_{3} \mathrm{C}_{2} \mathrm{~T}_{x}$ nanosheets and $\mathrm{Ti}_{3} \mathrm{C}_{2} \mathrm{~T}_{x} / \mathrm{PB}$ composite. The image of lignin/PVA/urea precursor solutions, lignin/PVA/urea film, and LSG patterns. SEM images of N-LSG with different applied laser power. The figure of sheet resistances of LSG prepared with different $\mathrm{CO}_{2}$ laser power. High-resolution SEM image of $\mathrm{Ti}_{3} \mathrm{C}_{2} \mathrm{~T}_{x} / \mathrm{PB}$ composite. High-resolution TEM image of $\mathrm{Ti}_{3} \mathrm{C}_{2} \mathrm{~T}_{x} / \mathrm{PB}$ composite. The figure of chronoamperometric responses of glucose and lactate sensor. The figure of Cyclic voltammetry (CV) corresponding to the electroreduction of hydrogen peroxide on the $\mathrm{Ti}_{3} \mathrm{C}_{2} \mathrm{~T}_{x} / \mathrm{PB} / \mathrm{N}-\mathrm{LSG} 4.8$ electrode.

\section{AUTHOR INFORMATION}

\section{Corresponding Author}

*E-mail: sahika.inal@kaust.edu.sa 


\section{ORCID}

Sahika Inal: 0000-0002-1166-1512

Yongjiu Lei: 0000-0003-1663-6102

\section{Notes}

The authors declare no competing financial interest.

\section{ACKNOWLEDGMENTS}

Research reported in this publication was supported by King Abdullah University of Science and Technology (KAUST).

\section{REFERENCES}

(1) Yang, W.; Ratinac, K. R.; Ringer, S. P.; Thordarson, P.; Gooding, J. J.; Braet, F. Carbon Nanomaterials in Biosensors: Should You Use Nanotubes or Graphene? Angew. Chem., Int.

Ed. 2010, 49, 2114-2138.

(2) Ndamanisha, J. C.; Guo, L. Ordered Mesoporous Carbon for Electrochemical Sensing: A Review. Anal. Chim. Acta 2012, 747, 19-28.

(3) Shao, Y.; Wang, J.; Wu, H.; Liu, J.; Aksay, I. A.; Yuehe Lin, Y. Graphene Based Electrochemical Sensors and Biosensors: A Review. Electroanalysis 2010, 22, 1027-1036.

(4) Wu, S.; He, Q.; Tan, C.; Wang, Y.; Zhang, H. Graphene-Based Electrochemical Sensors. Small 2013, 9, 1160-1172.

(5) Li, W.; Tan, C.; Lowe, M. A.; Abruna, H. D.; Ralph, D. C. Electrochemistry of Individual Monolayer Graphene Sheets. ACS Nano 2011, 5 (3), 2264-2270. 
(6) McCreery, R. L.; McDermott, M. T. Comment on Electrochemical Kinetics at Ordered Graphite Electrodes. Anal. Chem. 2012, 84, 2602-2605.

(7) Wu, Z. -S.; Sun, Y.; Tan, Y. -Z.; Yang, S.; Feng, X.; Müllen, K. Three-Dimensional Graphene-Based Macro- and Mesoporous Frameworks for High-Performance Electrochemical Capacitive Energy Storage. J. Am. Chem. Soc. 2012, 134 (48), $19532-19535$.

(8) Dong, X. -C.; Xu, H.; Wang, X. -W.; Huang, Y. -X.; Chan-Park, M. B.; Zhang, H.; Wang, L. -H.; Huang, W.; Chen, P. 3D Graphene-Cobalt Oxide Electrode for HighPerformance Supercapacitor and Enzymeless Glucose Detection. ACS Nano 2012, 6 (4), $3206-3213$.

(9) Wu, M.; Meng, S.; Wang, Q.; Si, W.; Huang, W.; Dong, X. Nickel-Cobalt Oxide Decorated Three-Dimensional Graphene as an Enzyme Mimic for Glucose and Calcium Detection. ACS Appl. Mater. Interfaces 2015, 7, 21089-21094.

(10) Li, N.; Zhang, Q.; Gao, S.; Song, Q.; Huang, R.; Wang, L.; Liu, L.; Dai, J.; Tang, M.; Cheng, G. Three-Dimensional Graphene Foam as A Biocompatible and Conductive Scaffold for Neural Stem Cells. Sci. Rep-Uk 2013, 3, DOI: 10.1038/srep01604.

(11) Griffiths, K.; Dale, C.; Hedley, J.; Kowal, M. D.; Kaner, R. B.; Keegan, N. LaserScribed Graphene Presents an Opportunity to Print A New Generation of Disposable Electrochemical Sensors. Nanoscale, 2014, 6, 13613-13622. 
(12) Fenzl, C.; Nayak, P.; Hirsch, T.; Wolfbeis, O. S.; Alshareef, H. N.; Baeumner, A. J. Laser-Scribed Graphene Electrodes for Aptamer-Based Biosensing. ACS Sens. 2017, 2, $616-620$.

(13) Nayak, P.; Kurra, N.; Xia, C.; Alshareef, H. N. Highly Efficient Laser Scribed Graphene Electrodes for On-Chip Electrochemical Sensing Applications. Adv. Electron. Mater. 2016, 2, 1600185.

(14) Lin, J.; Peng, Z.; Liu, Y.; Ruiz-Zepeda, F.; Ye, R.; Samuel, E. L.G.; Yacaman, M. J.; Yakobson, B. I.; Tour, J. M. Laser-Induced Porous Graphene Films from Commercial Polymers. Nat. Commun. 2014, 5, DOI: 10.1038/ncomms6714.

(15) Chyan, Y.; Ye, R.; Li, Y.; Singh, S. P.; Arnusch, C. J. Tour, J. M. Laser-Induced Graphene by Multiple Lasing: Toward Electronics on Cloth, Paper, and Food. ACS Nano 2018, 12, 2176-2183.

(16) Le, T. -S. D.; Park, S.; An, J.; Lee, P. S.; Kim, Y. J. Ultrafast Laser Pulses Enable OneStep Graphene Patterning on Woods and Leaves for Green Electronics. Adv. Funct. Mater. 2019, 29, 1902771.

(17) Mota, G. S.; Sartori, C. J.; Ferreira, J.; Miranda, I.; Quilhó, T.; Mori, F. A.; Pereira, H. Cellular Structure and Chemical Composition of Cork from Plathymenia Reticulata Occurring in the Brazilian Cerrado. Ind. Crops Prod. 2016, 90, 65-75.

(18) Daud, W. M. A. W.; Ali, W. S. W. Comparison on Pore Development of Activated Carbon Produced from Palm Shell and Coconut Shell. Bioresour. Technol. 2004, 93, 63-69. 
(19) Aro, T.; Fatehi, P. Production and Application of Lignosulfonates and Sulfonated Lignin. ChemSusChem. 2017, 10, 1861-1877.

(20) Zhang, F.; Alhajji, E.; Lei, Y.; Kurra, N.; Alshareef, H. A. Highly Doped 3D Graphene Na-Ion Battery Anode by Laser Scribing Polyimide Films in Nitrogen Ambient. Adv. Energy Mater. 2018, 8, 1800353.

(21) Dreyfus, R. W. CN Temperatures above laser ablated polyimide. Appl. Phys. A, 1992, $55,335-339$.

(22) Botas, C.; A'lvarez, P.; Blanco, C.; Santamarı'a, R.; Granda, M.; Gutie'rrez, M. D.;

Rodrı'guez-Reinoso, F.; Mene'ndez, R. Critical Temperatures in the Synthesis of Graphene-Like Materials by Thermal Exfoliation-Reduction of Graphite Oxide. Carbon 2013, 52, 476-485.

(23) Ferrari, A. C.; Meyer, J. C.; Scardaci, V.; Casiraghi, C.; Lazzeri, M.; Mauri, F.; Piscanec, S.; Jiang, D.; Novoselov, K. S.; Roth, S.; Geim, A. K. Raman Spectrum of Graphene and Graphene 2014Layers. Phys. Rev. Lett. 2006, 97, 187401.

(24) Cançado, L. G.; Takai, K.; Enoki, T.; Endo, M.; Kim, Y. A.; Mizusaki, H.; Jorio, A.; Coelho, A. J. L. N.; Magalhães-Paniago, R.; Pimenta, M. A. General Equation for the Determination of the Crystallite Size $\mathrm{L}_{\mathrm{a}}$ of Nanographite by Raman Spectroscopy. Appl. Phys. Lett. 2006, 88, 163106.

(25) Wu, J. -B.; Lin, M. -L.; Cong, X.; Liu, H. -N.; Tan, P. -H. Raman Spectroscopy of Graphene-Based Materials and Its Applications in Related Devices. Chem. Soc. Rev. 2018, 47, 1822-1873. 
(26) Bard, A. J.; Faulkner, L. R. Electrochemical Methods: Fundamentals and Applications, 2nd ed., John Wiley \& Sons, New York 2010.

(27) Wang, Y.; Limon-Petersen, J. G.; Compton, R. G. Measurement of the Diffusion Coefficients of $\left[\mathrm{Ru}\left(\mathrm{NH}_{3}\right)_{6}\right]^{3+}$ and $\left[\mathrm{Ru}\left(\mathrm{NH}_{3}\right)_{6}\right]^{2+}$ in Aqueous Solution Using Microelectrode Double Potential Step Chronoamperometry. J. Electroanal. Chem. 2011, 652, 13-17.

(28) Nicholson, R. S. Theory and Application of Cyclic Voltammetry for Measurement of Electrode Reaction Kinetics. Anal. Chem. 1965, 37, 1351-1355.

(29) Brownson, D. A. C.; Varey, S. A.; Hussain, F.; Haigh, S. J.; Banks, C. E. Electrochemical Properties of CVD Grown Pristine Graphene: Monolayer- vs. Quasi Graphene. Nanoscale, 2014, 6, 1607-1621.

(30) Davies, T. J.; Moore, R. R.; Banks, C. E.; Compton, R. G. The Cyclic Voltammetric Response of Electrochemically Heterogeneous Surfaces. J. Electroanal. Chem. 2004, 574, $123-152$.

(31) Martinez, A. W.; Phillips, S. T.; Butte, M. J.; Whitesides, G. M. Patterned Paper as a Platform for Inexpensive, Low-Volume, Portable Bioassays. Angew. Chem., Int. Ed. 2007, $46,1318-1320$.

(32) Amor-Gutiérrez, O.; Rama, E. C.; Costa-García, A.; Fernández-Abedul, M. T. PaperBased Maskless Enzymatic Sensor for Glucose Determination Combining Ink and Wire Electrodes. Biosens. Bioelectron. 2017, 93 (15), 40-45. 
(33) Costa, T. H. D.; Song, E.; Tortorich, P. R.; Choi, J. -W. A Paper-Based Electrochemical Sensor Using Inkjet-Printed Carbon Nanotube Electrodes. ECS J. Solid State Sci. Technol. 2015, 4 (10), S3044-S3047.

(34) Dungchai, W.; Chailapakul, O.; Henry, C. S. Electrochemical Detection for PaperBased Microfluidics. Anal. Chem. 2009, 81, 5821-5826.

(35) Oncescu, V.; O’Dell, D.; Erickson, D. Smartphone Based Health Accessory for Colorimetric Detection of Biomarkers in Sweat and Saliva. Lab Chip 2013, 13, 3232-3238.

(36) Shen, L.; Hagen, J. A.; Papautsky, I. Point-of-Care Colorimetric Detection with a Smartphone. Lab Chip 2012, 12, 4240-4243.

(37) Kim, J.; Jeerapan, I.; Imani, S.; Cho, T. N.; Bandodkar, A.; Cinti, S.; Patrick P. Mercier, P. P.; Wang, J. Noninvasive Alcohol Monitoring Using a Wearable Tattoo-Based Iontophoretic-Biosensing System. ACS Sens. 2016, 1, 1011-1019.

(38) Sonner, Z.; Wilder, E.; Heikenfeld, J.; Kasting, G.; Beyette, F.; Swaile, D.; Sherman, F.; Joyce, J.; Hagen, J.; Kelley-Loughnane, N.; Naik, R. The Microfluidics of the Eccrine Sweat Gland, Including Biomarker Partitioning, Transport, and Biosensing Implications. Biomicrofluidics 2015, 9, 031301.

(39) Heikenfeld, J. Non-Invasive Analyte Access and Sensing through Eccrine Sweat: Challenges and Outlook circa 2016. Electroanalysis 2016, 28, 1242-1249.

(40) Lee, H.; Song, C.; Hong, Y. S.; Kim, M. S.; Cho, H. R.; Kang, T.; Shin, K.; Choi, H.; Hyeon, T.; Kim, D. -H. Wearable/Disposable Sweat-Based Glucose Monitoring Device with Multistage Transdermal Drug Delivery Module. Sci. Adv. 2017, 3, e1601314. 
(41) Lei, Y.; Zhao, W.; Zhang, Y.; Jiang, Q.; He, J. -H.; Baeumner, A. J.; Wolfbeis, O. S.; Wang, Z. L.; Salama, K. N.; Alshareef, H. N. A MXene-Based Wearable Biosensor System for High-Performance In Vitro Perspiration Analysis. Small 2019, 15, 1901190.

(42) Green, J. M.; Pritchett, R. C.; Crews, T. R.; Jr, J. R. M.; Tucker, D. C. Sweat Lactate Response Between Males with High and Low Aerobic Fitness. Eur. J. Appl. Physiol. 2004, $91,1-6$.

(43) Martín, A.; Kim, J.; Kurniawan, J. F.; Sempionatto, J. R.; Moreto, J. R.; Tang, G.; Campbell, A. S.; Shin, A.; Lee, M. Y.; Liu, X.; Wang, J. Epidermal Microfluidic Electrochemical Detection System: Enhanced Sweat Sampling and Metabolite Detection. ACS Sens. 2017, 2, 1860-1868. 


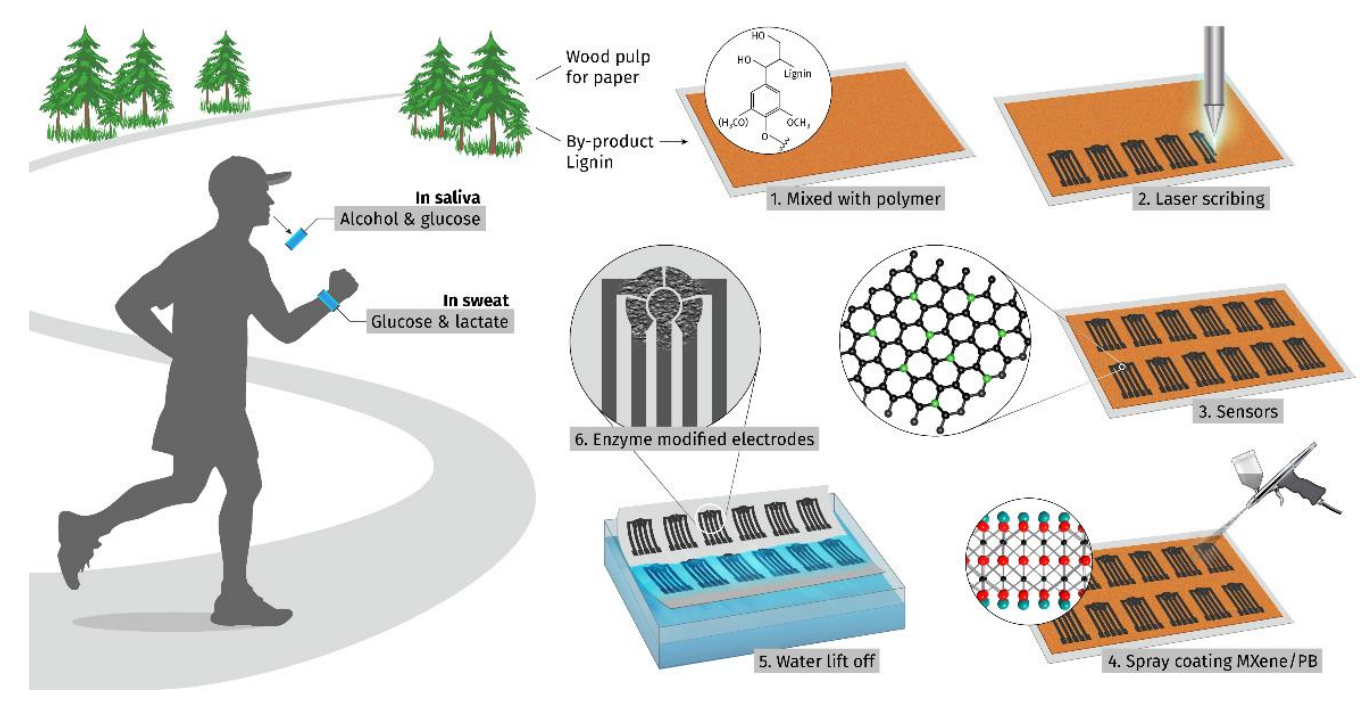

Figure 1. Scheme of the direct-write laser scribing process of N-LSG. (1) Preparation of lignin/PVA/urea film onto a substrate using a doctor blading method, (2) direct-write laser scribing process for preparing N-LSG from lignin/PVA/urea film, (3) the laser-scribed NLSG electrodes pattern, (4) the working electrodes modified with $\mathrm{Ti}_{3} \mathrm{C}_{2} \mathrm{~T}_{x} / \mathrm{PB}$ by spraying coating, (5) water lift-off process used to remove the uncarbonized film, and (6) the modification of N-LSG electrodes with enzymes. 

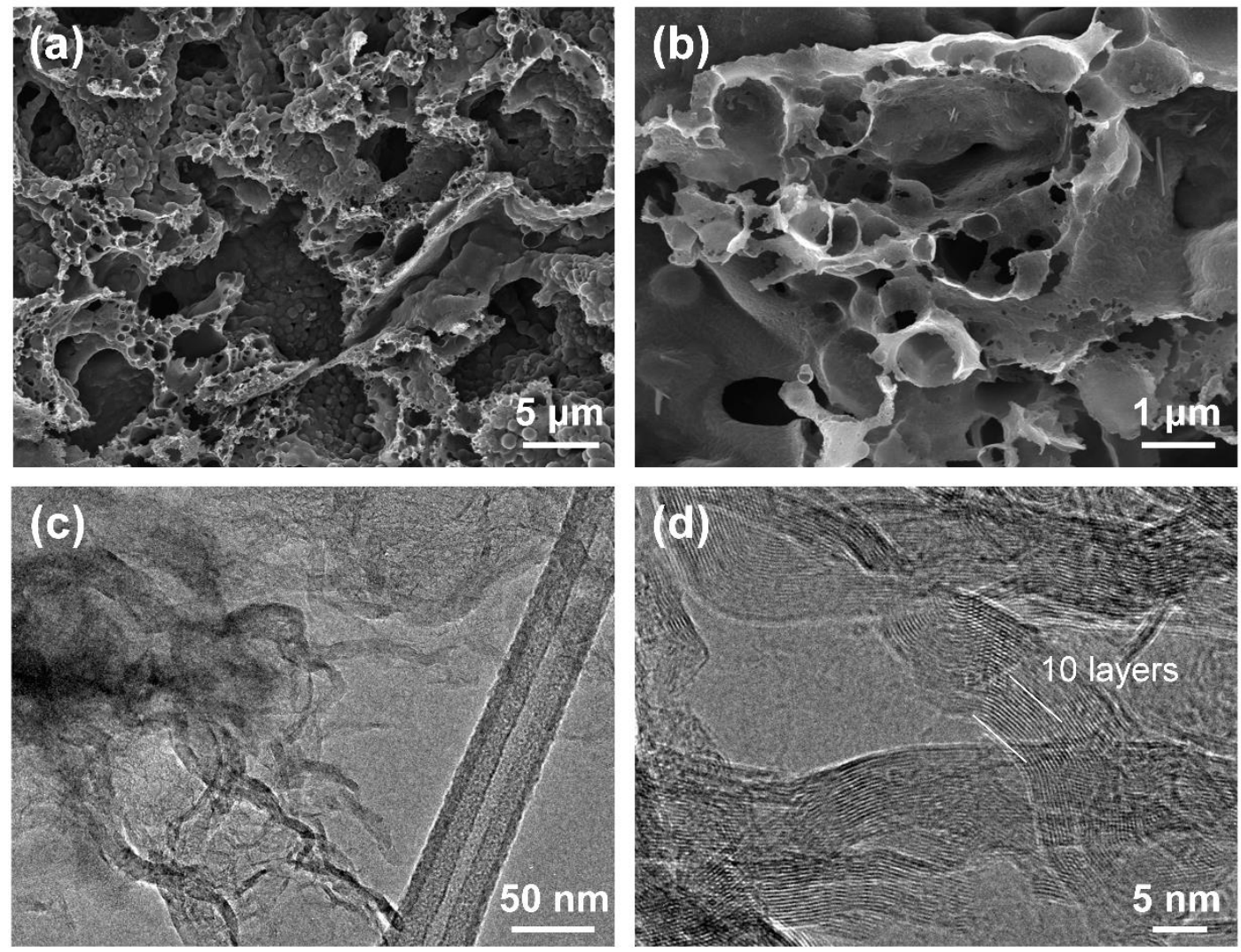

Figure 2. (a,b) SEM images of the N-LSG electrode prepared using 4.8\% laser power (NLSG4.8), low-resolution (c) and high-resolution (d) TEM images of the N-LSG4.8 electrode. 

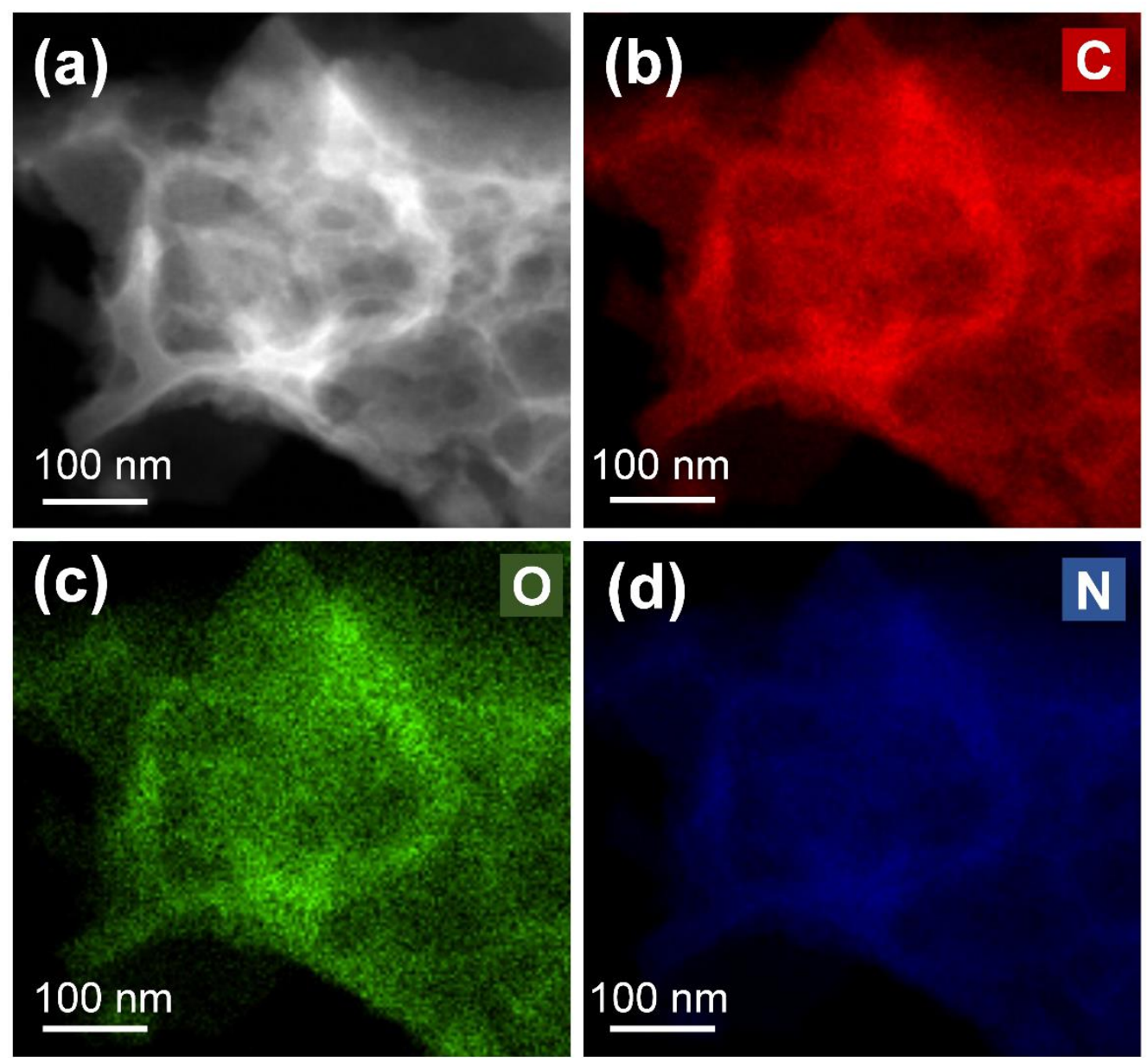

Figure 3. (a) STEM image of the N-LSG4.8 electrode, and the corresponding EDX elemental mapping of C (b), $\mathrm{O}(\mathrm{c})$, and $\mathrm{N}(\mathrm{d})$. 

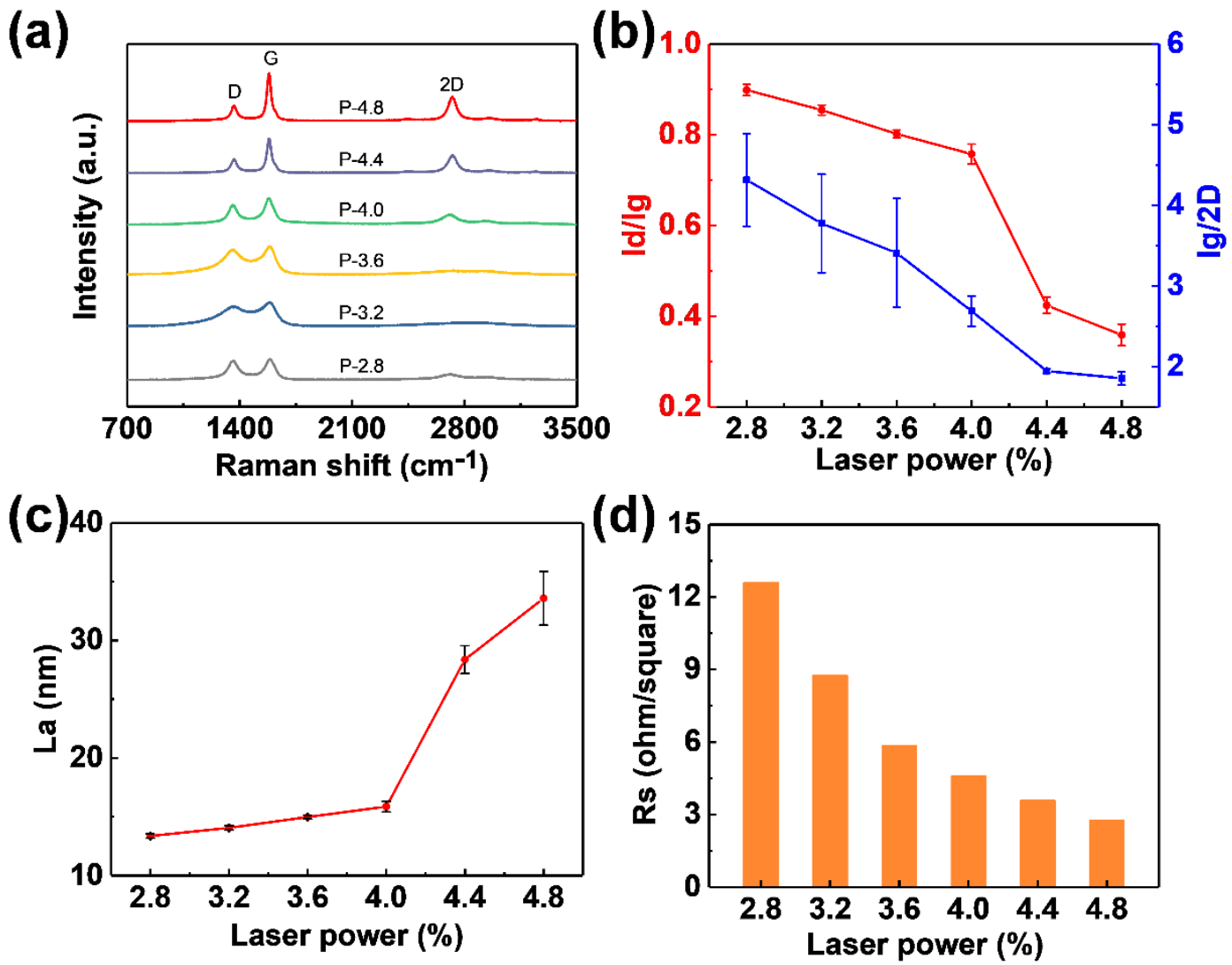

Figure 4. Physicochemical properties of lignin-derived N-LSG. (a) Raman spectra of the N-LSG electrodes fabricated using different laser powers, (b) the influence of laser powers on $I_{\mathrm{D}} / I_{\mathrm{G}}$ and $I_{\mathrm{D}} / I_{2 \mathrm{D}}$ ratios (b) and $L_{\mathrm{a}}(\mathrm{c})$, (d) the sheet resistances of N-LSG films prepared with different $\mathrm{CO}_{2}$ laser power. 

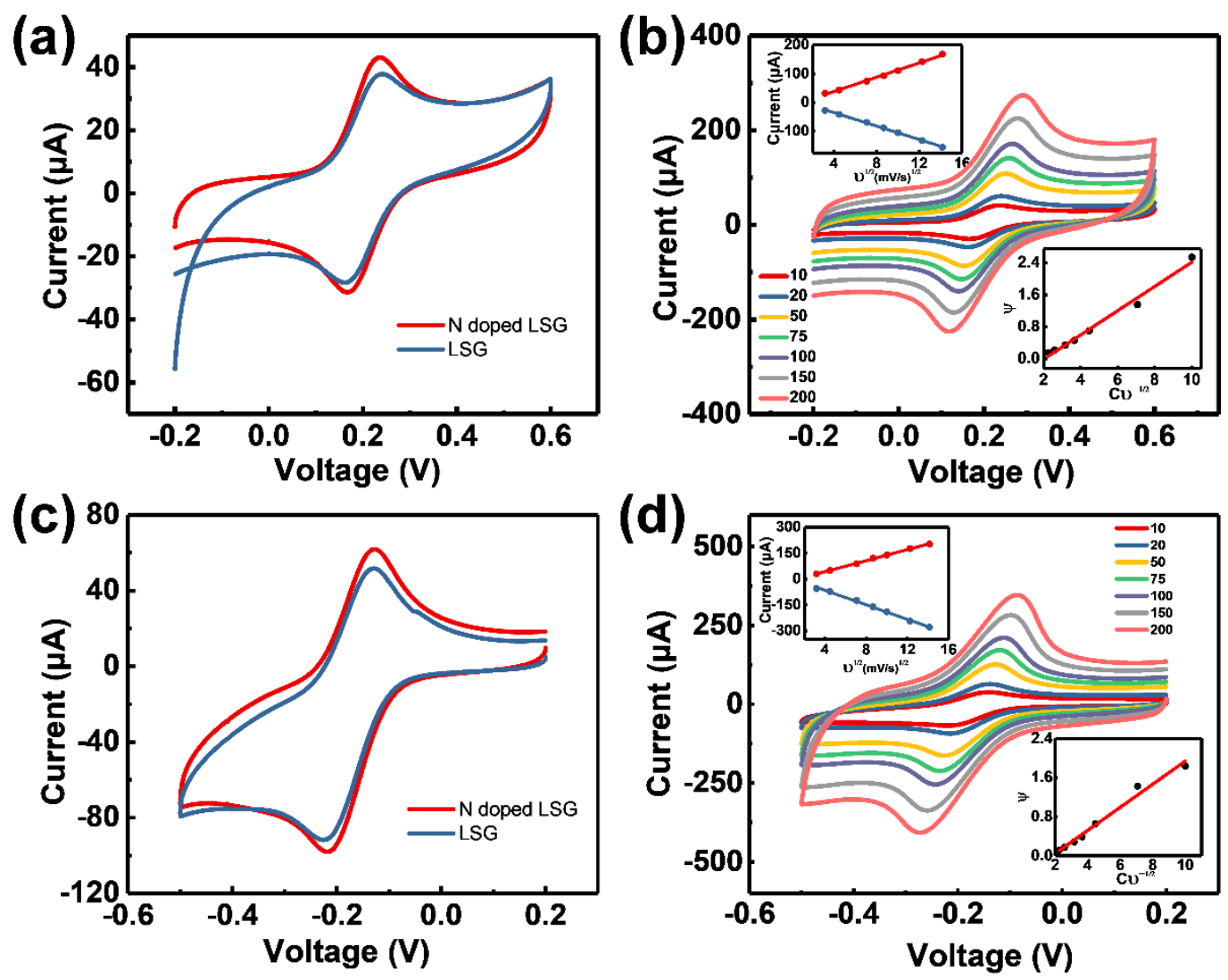

Figure 5. CV profiles of the LSG4.8 and N-LSG4.8 electrodes. CVs were acquired with (a) $5 \times 10^{-3} \mathrm{M}\left[\mathrm{Fe}(\mathrm{CN})_{6}\right]^{4-}$ and (c) $5 \times 10^{-3} \mathrm{M}\left[\mathrm{Ru}\left(\mathrm{NH}_{3}\right)_{6}\right]^{3+}\left(\right.$ scan rate: $10 \mathrm{mV} \mathrm{s}^{-1}$ ). $\mathrm{CV}$ plots of (b) $5 \times 10^{-3} \mathrm{M}\left[\mathrm{Fe}(\mathrm{CN})_{6}\right]^{4-}$ and (d) $5 \times 10^{-3} \mathrm{M}\left[\mathrm{Ru}\left(\mathrm{NH}_{3}\right)_{6}\right]^{3+}$ at different scan rates for N-LSG4.8 electrodes. Upper left insets show the measured peak currents $\left(I_{\mathrm{p}}\right) v s . v^{1 / 2}$. Lower right insets are the plots of Nicholson's kinetic parameter $\Psi v s . \mathrm{Cv}^{-1 / 2}$. 

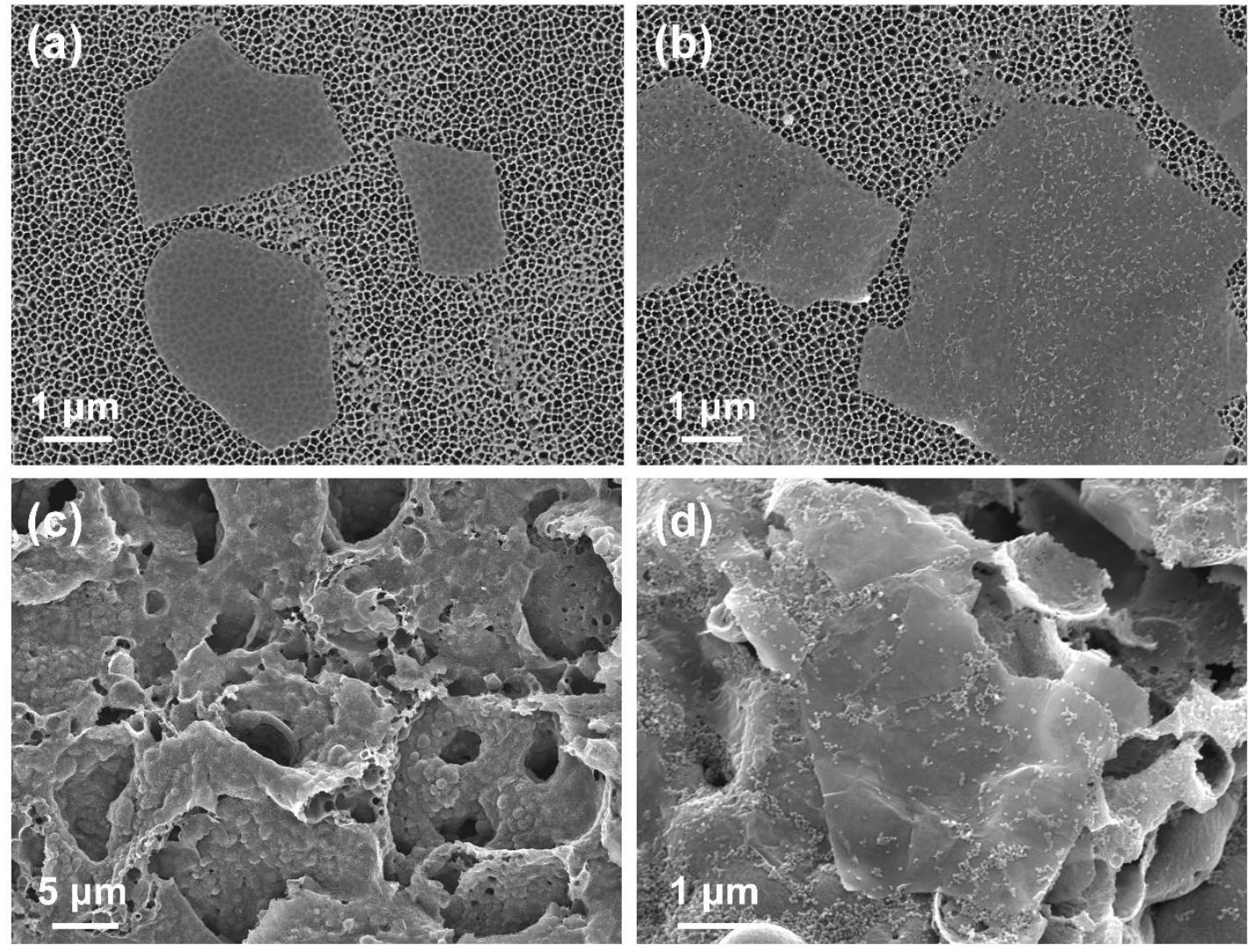

Figure 6. SEM images of (a) $\mathrm{Ti}_{3} \mathrm{C}_{2} \mathrm{~T}_{x}$ flakes deposited on porous alumina membrane, (b) as-synthesized $\mathrm{Ti}_{3} \mathrm{C}_{2} \mathrm{~T}_{x} / \mathrm{PB}$ nanocomposites on porous alumina membrane, (c) $\mathrm{Ti}_{3} \mathrm{C}_{2} \mathrm{~T}_{x} / \mathrm{PB} / \mathrm{N}-\mathrm{LSG} 4.8$ electrode, and (d) a zoomed-in SEM image of the $\mathrm{Ti}_{3} \mathrm{C}_{2} \mathrm{~T}_{x} / \mathrm{PB} / \mathrm{N}-$ LSG4.8 electrode. 

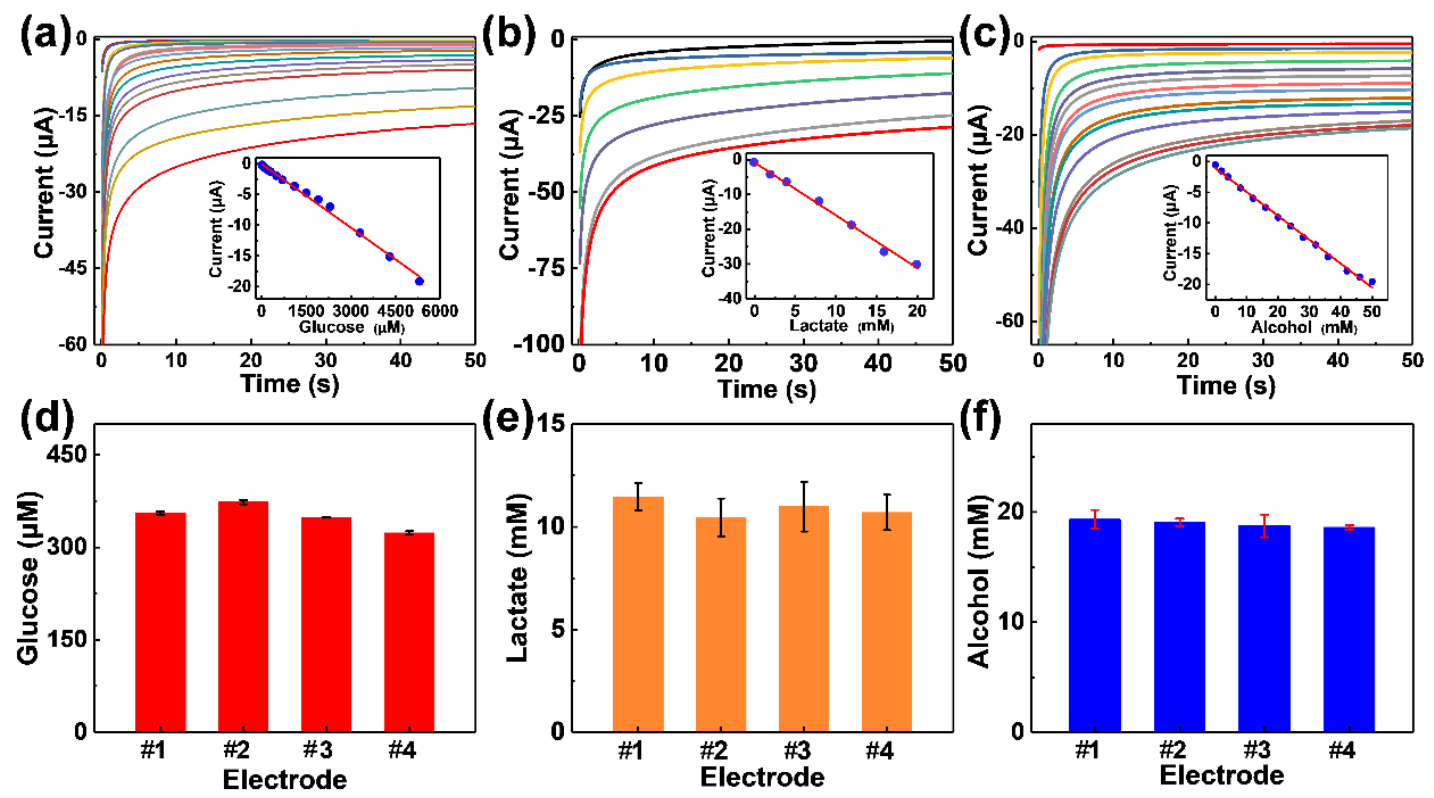

Figure 7. CA plots of (a) the glucose sensor (0 to $5.3 \mathrm{mM}$ in artificial sweat), (b) the lactate sensor (0 to $20 \mathrm{mM}$ in artificial sweat), and (c) the alcohol sensor (0 to $50 \mathrm{mM}$ in artificial sweat). The insets of Figure 7a-c give the calibration curves of the corresponding sensors on recording the current at $40^{\text {th }}$ second after bias application. (d-f) CA profiles of the same batch of glucose, lactate, and alcohol sensors to artificial sweat containing $350 \mu \mathrm{M}$ glucose, $10 \mathrm{mM}$ lactate, and $20 \mathrm{mM}$ of alcohol to verify the reproducibility of the sensors. 
Table 1. Stochastic electrochemical performance metrics of N-LSG4.8 electrodes

\begin{tabular}{cccccc}
\hline \multirow{2}{*}{ Electrodes } & $\begin{array}{c}\text { Electrochemically } \\
\text { active surface } \\
\text { area S }\left(\mathrm{mm}^{2}\right)\end{array}$ & \multicolumn{2}{c}{$\left[\mathrm{Fe}(\mathrm{CN})_{6}\right]^{4-}$} & \multicolumn{2}{c}{$\left[\mathrm{Ru}\left(\mathrm{NH}_{3}\right)_{6}\right]^{3+}$} \\
\cline { 2 - 6 } $\mathbf{1}$ & 12.89 & 68 & 0.00873 & 72 & 0.00903 \\
$\mathbf{2}$ & 12.35 & 71 & 0.0085 & 74 & 0.00862 \\
$\mathbf{3}$ & 12.65 & 70 & 0.0086 & 73 & 0.009 \\
$\mathbf{4}$ & 12.67 & 67 & 0.0109 & 72 & 0.0091 \\
$\mathbf{5}$ & 11.32 & 72 & 0.0083 & 75 & 0.00738 \\
Average & 12.376 & 69.6 & 0.00903 & 73.2 & 0.00863 \\
RSD & $5.0 \%$ & $2.9 \%$ & $11.0 \%$ & $1.8 \%$ & $8.3 \%$ \\
\hline
\end{tabular}


For Table of Contents Only:

\section{Laser-Scribed Graphene Electrodes Derived from Lignin for Biochemical Sensing}

A patterning process for highly conductive nitrogen-doped porous graphene derived from lignin-based precursor was developed. The nitrogen-doped laser-scribed graphene with its binder-free, hierarchical, conductive 3D interconnected carbon network has displayed enhanced electrochemical activity with fast heterogeneous electron transfer.

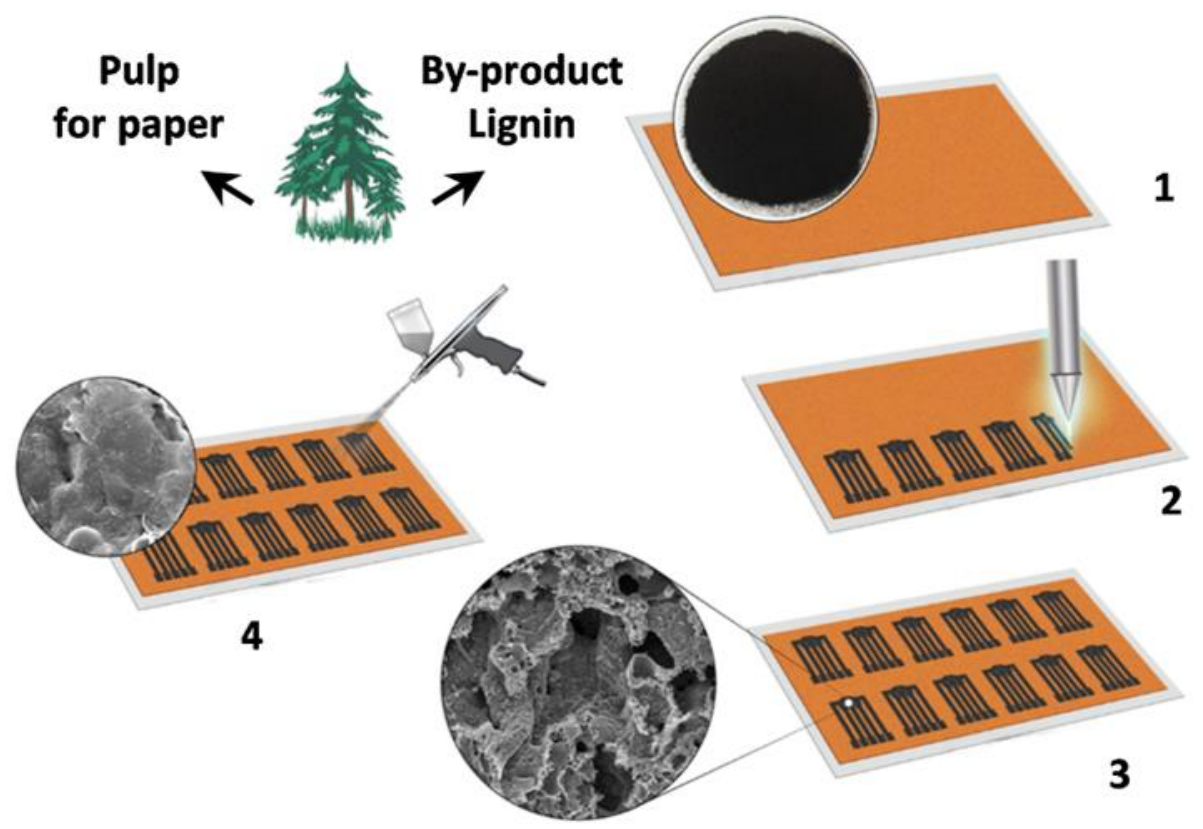

